\title{
Holistic Vehicle Simulation using Modelica - An Application on Thermal Management and Operation Strategy for Electrified Vehicles
}

\author{
Claude Bouvy \\ Forschungsgesellschaft Kraftfahrwesen mbH \\ Steinbachstraße 7, 52074 Aachen \\ bouvy@fka.de
}

\author{
Sidney Baltzer Peter Jeck Jörg Gissing Thomas Lichius Lutz Eckstein \\ Institut für Kraftfahrzeuge - RWTH Aachen University, Aachen \\ Steinbachstraße 7, 52074 Aachen \\ baltzer@ika.rwth-aachen.de
}

\begin{abstract}
The increasing electrification of the drive train in the automotive environment leads to higher requirements for automotive systems and their design. Therefore, a computer based methodology to support the engineer in the design phase of car concepts, components and control algorithms is desirable. All relevant sections of a vehicle development process, e.g. longitudinal and lateral dynamics, thermal management or the power supply should be considered. Due to this necessity a new holistic vehicle library is developed at the Forschungsgesellschaft Kraftfahrwesen $\mathrm{mbH}$ Aachen (fka) and Institute of Automotive Engineering (ika) of RWTH Aachen University. The introduced holistic method is applied exemplarily on architecture with the traction battery as thermal storage to determine the potential of such a design on the overall efficiency and to analyse different operational strategies.
\end{abstract}

Keywords: thermal management; vehicle simulation; traction battery, electric vehicle, range extender, thermal storage, control strategy

\section{Introduction}

Due to ecologic and economic reasons, the overall efficiency and the emissions, both local and global, of individual mobility have to be improved. An increased electrification of the drive train is currently being considered as a promising approach for reducing both the energy demand and the emissions. However, an increased electrification of the drive train, i.e. replacing or partly substituting the internal combustion engine, implies the integration of new components as well as a higher number of energy conversion units.

The augmented number of components, as well as their diverging requirements and operating conditions will clearly increase the complexity of electrified car architectures. On the thermal side for example, the integration of temperature sensitive components, e.g. lithium ion batteries, may imply more complex cooling circuit architectures, as the relevant operating temperatures clearly differ to those of an electric machine or an internal combustion engine. On a mechanical level for example, there are several possibilities to couple an internal combustion engine and an electric machine: e.g. parallel and serial hybrids.

Furthermore the increased efficiency of the electric machine compared to the internal combustion engine, will also increase the complexity of both the architecture and the operation strategies. For battery electric vehicles (BEV) for example, the cabin has to be heated by means of electric energy, as in general no or little waste heat is available at a sufficiently high temperature level. Thus, for highly electrified concepts the cabin heating will directly influence the drive train, the power net and the design of the control strategies. To minimise the used electric energy heat pump systems and improved heating control strategies are possible alternatives (cf. e.g. [1]).

The given examples clearly show that a strongly increased complexity has to be expected for the design phase of future cars. Currently an overall design ap- 
proach is missing. In general different and mostly incompatible tools are applied for different design tasks and the overall design process is strongly hierarchic. Up to now such a top-down approach was practicable, as the correlation of the energy flows was minor. In general the internal combustion engine, as the core energy conversion unit, implicated the design of most other units, e.g. the cooling circuit.

Furthermore, the different energy forms, chemical, mechanical, electrical and thermal, are increasingly correlated for electrified car concepts. The higher complexity as well as the necessity of a holistic approach requires new tools to support the engineer in the design process.

\section{Library description}

The holistic model library developed at Forschungsgesellschaft Kraftfahrwesen mbH Aachen (fka) and Institute of Automotive Engineering (ika) of RWTH Aachen University (cf. [2]) takes into consideration all energetic (mechanical, electrical, thermal and chemical) and logical (sensors, actors and control units) flows including dynamic boundary conditions (e.g. drive cycles, ambient conditions) of automotive concerns. It follows a layer based level approach. Basically the modeling library is structured as illustrated in Fig. 1.

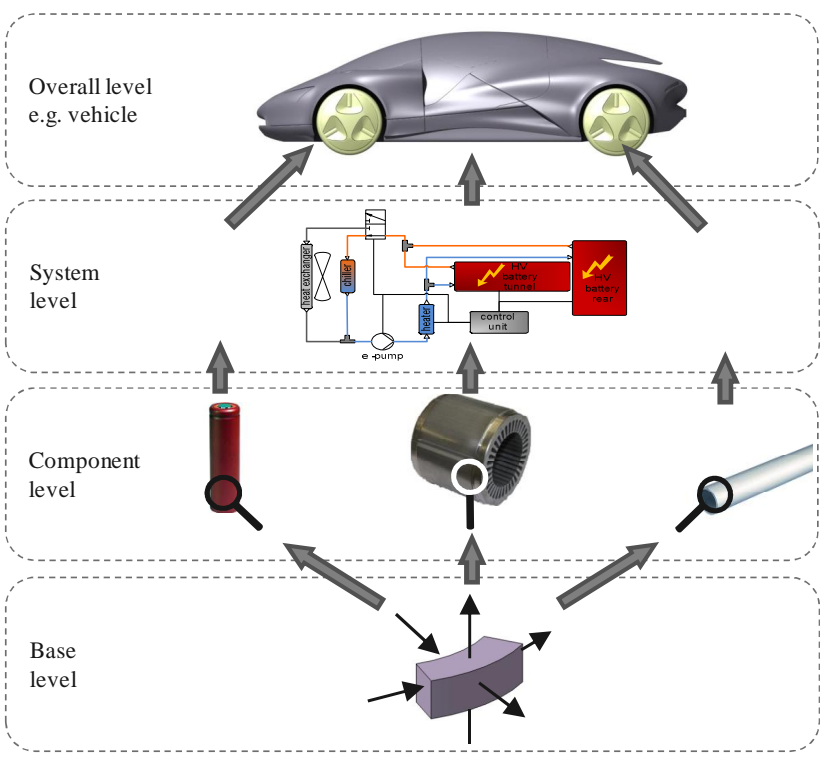

Fig. 1: The four level structure of the holistic tool

\subsection{Base Level}

At the lowest level generalized elements are implemented which can easily be adapted due to the object oriented modeling property of inheritance or instantiation. On the base level the following packages are implemented. All elements on that level are not computable and are combined later on the components level.

- ThermalLib

- ElectricLib

- MechanicLib

- StateModelLib

- Utilities

The ThermalLib contains all base classes of thermal concern. Based on a general volume element with generalized mass and energy balances and properties, a fluid and a solid element are derived and used for all calculations. Secondly the geometric information of these elements is defined.

For a fluid element the dynamic momentum balance is calculated. A variable modeling depth of pressure drop calculation method may be adapted by choosing a flow model. A heat transfer model calculates the coefficient of heat transfer and provides the necessary interface to e.g. the surrounding ambient. For the solids variable geometries are implemented based on a solidElement, so that new models can easily be generated on the components level. This is illustrated in Fig. 1 where a standardized shell element is used for electric machine housing, the tube of a heat exchanger or a cylindrical battery cell.

The other packages contain e.g. voltage sources (ElectricLib), inertias (MechanicLib) or general mathematical functions (Utilities).

The StateModelLib uses both a model based and a function based approach, wherein data of literature or specific measured fluids can be chosen.

For physical values thermal, fluid, electric and mechanical connectors are defined using the flow and stream properties. For the logical signals expandable connectors are used.

Interfaces are provided, so that the library stays compatible with the Modelica Standard Library connectors (cf. [3], [4]) and the Vehicle Interface Library (cf. [5]). 


\subsection{Component Level}

At the components level a variable number of base elements are combined to generate models to a chosen level of design. At present the components level has the following structure:

- HydraulicComponents

- DriveTrainComponents

- PassengerCabinComponents

E.g. tubes, valves, heat exchangers or pumps are elements of the Hydraulic Components, whereas gears, clutches, electric machines, internal combustion engines or the traction battery are part of the DriveTrainComponents. The different kinds of car body types are integrated e.g. in the Passenger CabinComponents. All the components inherit from the lower base class level as described above.

Fig. 2 demonstrates the approach of the library by the example of the traction battery. It consists of the electrical model, a thermal model and a Battery management system (BMS). All sub models are implemented as replaceable models. Depending on the issue to be investigated the level of detail may be chosen for the single models. However, for the detailed component design, e.g. the exact shape of the cooling duct of a battery pack, a strongly increased level of detail, i.e. a strongly discretised modelling of the coolant flow, is needed, to judge both the heat transfer and the pressure losses as Thermal model (cf. Fig. 2). For the electric model a modeling approach using manufacture data map or a more detailed calculation on the chemical level may be chosen. The BMS may be simulated as a single ReadOnly system or more intelligent systems including a control unit may be chosen.

The single models are linked via standardized connectors. For sensor models expandable connectors of the Modelica Standard Library (cf. [3]) are used.

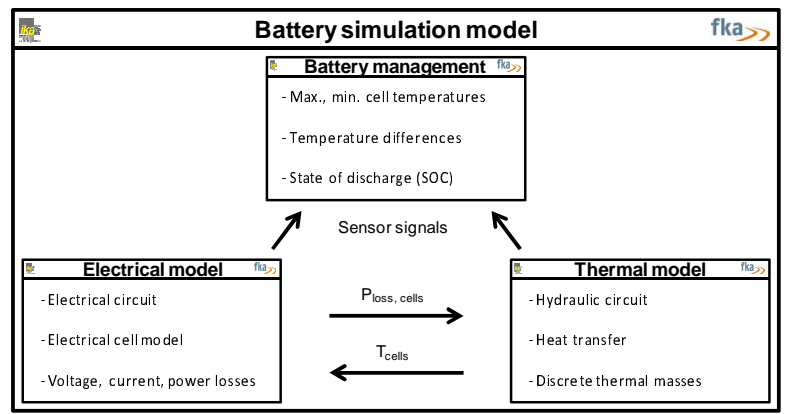

Fig. 2: Modeling approach of the traction battery

\subsection{System}

At the system level the interactions of energy and signal flow between all components are implemented. The thermal fluid part of the system level is exemplarily shown for the low temperature cooling circuit of a battery electric vehicle in Fig. 3:

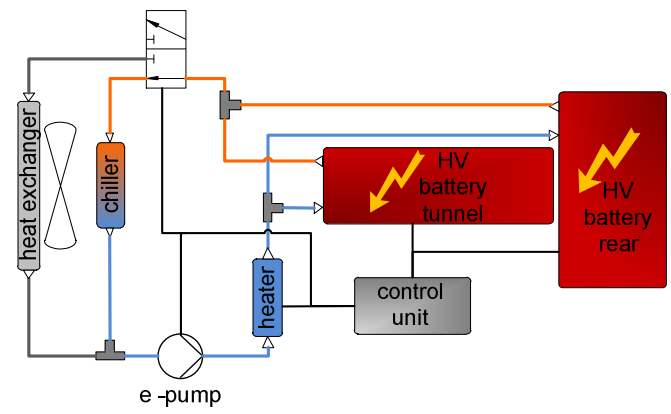

Fig. 3: schematic diagram of a battery cooling circuit

Fig. 4 shows the respective exemplary Modelica model of the configuration, including electrical, thermal and logical signals.

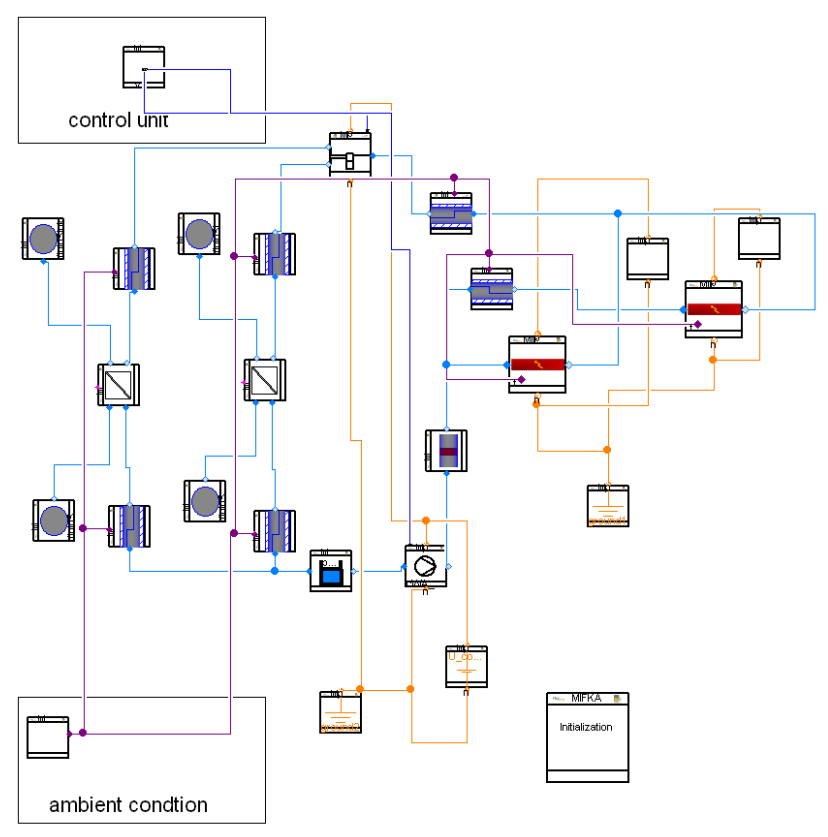

Fig. 4: Examplary model of the battery circuit

\subsection{Overall Level}

The vehicle level combines all vehicle sub models such as the power train, the respective cooling circuits, the power supply and the passenger cabin.

Beside the global boundary conditions, such as the driving cycle, the route profile, ambient conditions 
or initial conditions a control block which consists of the driver and the ECU manages all concerns of control.

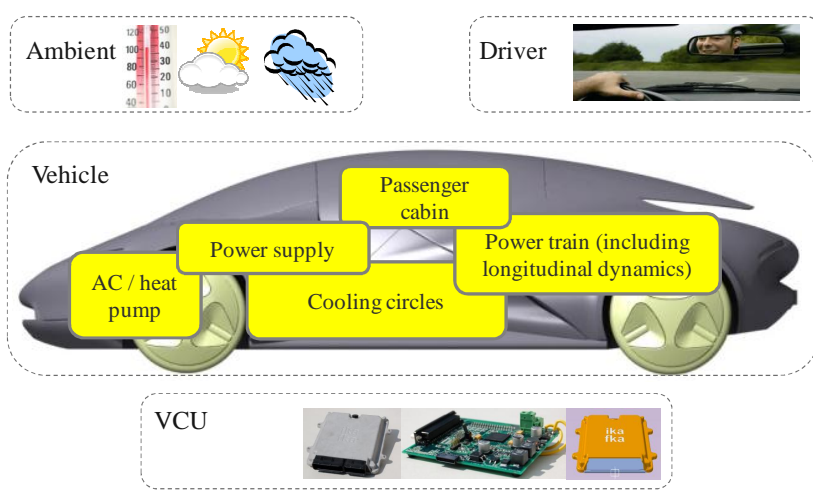

Fig. 5: schematic view of the overall level

\section{The traction battery as thermal storage for range extended vehicles}

In this chapter an application example is given for the use of the holistic vehicle simulation model approach.

A major challenge for electrified vehicles is to cover the heating demand for the passenger cabin in an efficient way. As stated in Bouvy et al., (cf. [6]) the application of a heat pump system in combination with a preheated traction battery as heat source provides an efficient solution for passenger cabin heating, leading to higher range. In most cases the heat losses of the battery and the thermal capacity are not high enough to cover the heat demand of the passenger cabin so the battery cools down. To avoid an underrun of a critical minimal cell temperature an additional electric heater needs to be switched on so the overall energetic benefit is rather low. Regarding a range extended electric vehicle the waste heat of the internal combustion engine may, besides providing the heat for the passenger cabin, be used to reheat the battery. By this, the overall efficiency of this cogeneration (i.e. producing heat and power) unit may be maximized. Bouvy et al. (cf. [7]) have shown the important benefit of a cogeneration unit on the efficiency of passenger cars.

\subsection{System architectures}

For this paper two system architectures are discussed for a $\mathrm{BEV}$ with a range extender unit.
The first one represents a state of the art range extender design. The cooling circuit of the range extender is connected to the heating and ventilation and air conditioning unit (HVAC) so its waste heat may be used for cabin heating. An additional heat pump system is not considered in this scenario and thermal peak loads are covered by a high voltage electric heater. The operation strategy of the range extender is SOC controlled: it starts when the SOC reaches $20 \%$ and is turned off at a value of $30 \%$ (Charge Sustaining - Mode). The schematic vehicle architecture is illustrated in Fig. 6.

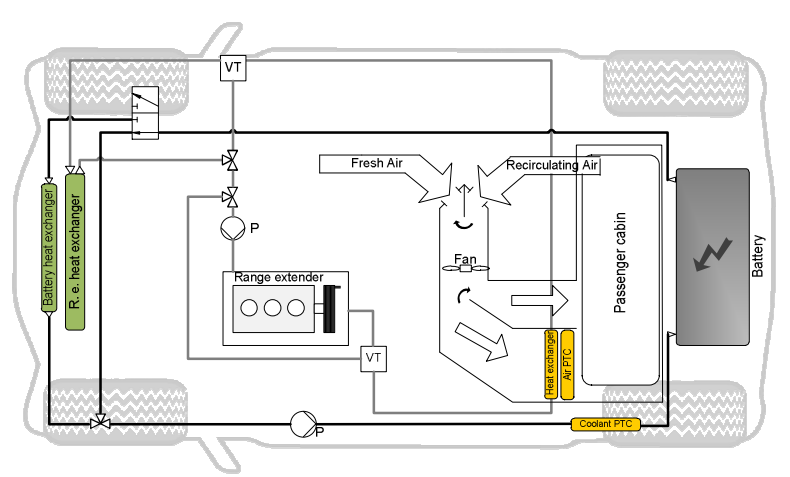

Fig. 6: Vehicle architecture 1

For the second architecture the internal combustion engine cooling circuit is connected to the battery cooling circuit by a fluid/fluid heat exchanger (cf. Fig. 7). Due to this design the battery can be thermally charged. A heat pump system is considered using the battery as heat source to provide an energy efficient heating of the passenger cabin when the internal combustion engine is turned off. The operation strategy of the range extender is thermally controlled by a two level controller. To keep the cell temperatures of the traction battery within an optimal range, the two temperature margins are set to $20^{\circ} \mathrm{C}$ and $30^{\circ} \mathrm{C}$. This operation strategy guarantees high coefficients of performance (COPs) of the heat pump system and an excessive cool down of the battery is avoided.

For both architectures the thermal peak loads of the passenger cabin heating demand are covered by an electric high voltage heater $(5 \mathrm{~kW})$. 


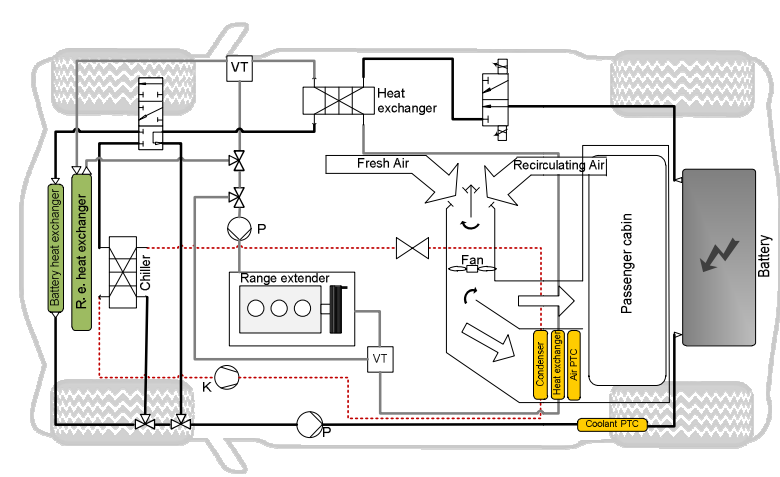

Fig. 7: Vehicle architecture 2

\subsection{Simulation setup}

In this analysis both layouts have a $44 \mathrm{~kW}$ range extender unit, an $80 \mathrm{~kW}$ ASM electric engine and a lithium-ion-battery with a nominal capacity of $8.6 \mathrm{kWh}$ (about $40 \mathrm{~km} \mathrm{BEV}$ range determined on the basis of the NEDC). The data are chosen according to Hartmann and Renner (cf. [8]).

The defined vehicle has a cabin volume of $3 \mathrm{~m}^{3}$ and a surrounding window surface of about $2 \mathrm{~m}^{2}$. For the determination of the cabin heat demand a single passenger is assumed and the HVAC is controlled by the passenger cabin air temperature according to Strupp and Lemke (cf. [10]).

All simulations are performed for a Central European winter scenario with an ambient temperature of $0{ }^{\circ} \mathrm{C}$ and solar radiation values according to Strupp and Lemke (cf. [10]). At simulation start all thermal masses are in equilibrium at ambient condition. The battery is conditioned to allow regenerative braking immediately at the beginning of the simulation ride ( 5 consecutive NEDCs). The preconditioning is performed by a $5 \mathrm{~kW}$ externally supplied electric heater. More detailed information concerning model depth and simulation setup can be found in Bouvy et al. (cf. [9]).

\subsection{Operational strategies}

For the first architecture the battery is electrically charged $(\mathrm{SOC}=90 \%)$ and thermally preconditioned, so that a min. cell temperature of $5{ }^{\circ} \mathrm{C}$ is reached. The internal combustion engine only operates in the "Charge sustaining modus". The internal combustion engine is operated with the power corresponding to the lowest specific fuel consumption to charge the battery. If an SOC of $30 \%$ is reached, the range extender is deactivated (state of the art operation of a range extender).

For the second architecture a thermal operation strategy is applied. The battery is thermally condi- tioned similar to variant 1 but a lower SOC is chosen to enable electric and thermal charging from the beginning on. A reduced operating power of the range extender is chosen, in order to better fit the power to heat ratio to demand (cf. [7], [11]).

\begin{tabular}{|l|l|l|}
\hline Variant & $\begin{array}{l}\text { Operational } \\
\text { Strategy }\end{array}$ & $\begin{array}{l}\text { Range Ex- } \\
\text { tender Control } \\
\text { Strategy }\end{array}$ \\
\hline $1^{\text {st }}$ & $\begin{array}{l}\text { Without using } \\
\text { battery as ther- } \\
\text { mal storage }\end{array}$ & $\begin{array}{l}\text { SOC controlled } \\
\mathrm{P}_{\text {mech }}=19000 \\
\mathrm{~W}\end{array}$ \\
\hline $2^{\text {nd }}$ & $\begin{array}{l}\text { Using battery as } \\
\text { thermal storage } \\
\text { Without battery } \\
\text { preheating }\end{array}$ & $\begin{array}{l}\text { Thermally con- } \\
\text { trolled } \\
\mathrm{P}_{\text {mech }}=10000 \\
\mathrm{~W}\end{array}$ \\
\hline
\end{tabular}

Tab. 1: Investigated variants

In Fig. 8 the Dymola model of the overall system level is shown for the analysed szenarios.

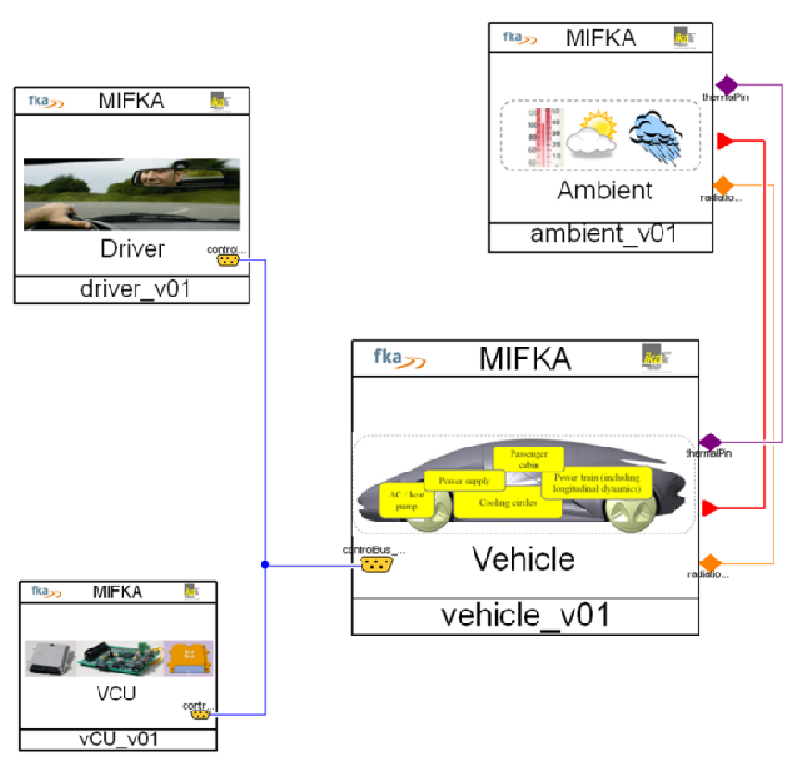

Fig. 8: overall system level in Dymola

\section{Simulation Results}

Fig. 9 shows the dynamic profile of the average cell temperatures. After the preconditioning phase the thermally operated range extender of variant 2 is turned on. At beginning the thermostatic valve of the internal combustion engine is closed until the ther- 
mal masses are heated up. Afterwards the waste heat is used both for cabin heating and to thermally charge the traction battery to a temperature of $30^{\circ} \mathrm{C}$. When reaching the threshold the engine is turned off and the heat pump system cools down the traction battery by providing the heating demand for the passenger cabin.

For variant 1 the battery slowly heats up due to charge/discharge losses.

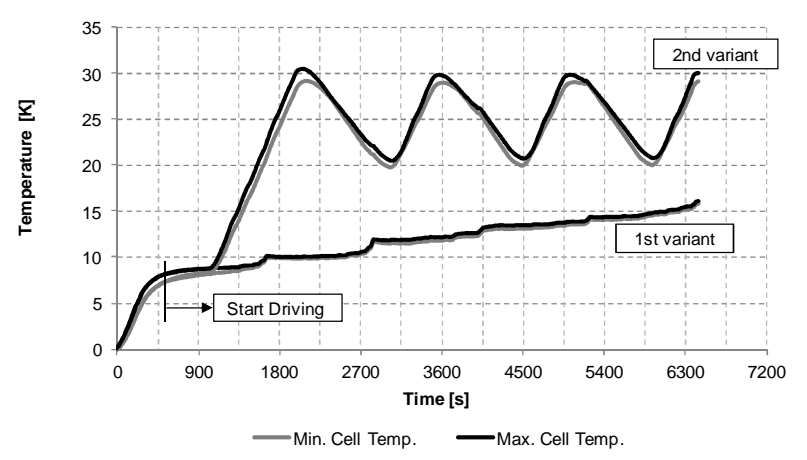

Fig. 9: average cell temperature for the simulated variants

Fig. 10 visualizes the time dependent state of charge curve. Variant 1 is operated purely electrically in the charge depleting mode until the defined SOC of $20 \%$ is reached. Subsequently the range extender is turned on after and the battery is charged again to a SOC of $30 \%$ (charge-sustaining).

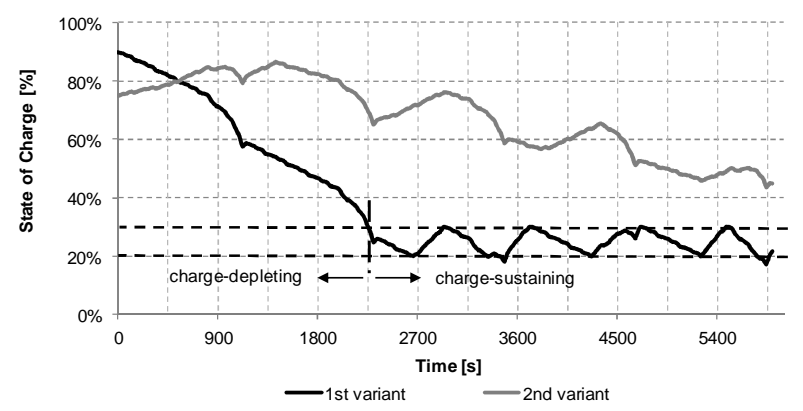

Fig. 10: State of charge of each variant

The operating times vary due to the power requirement for the drive cycle as seen in the velocity profile in Fig. 11.

In the second variant the engine is turned off at about 23 minutes. Over the whole ride the SOC is depleting because of the thermally controlled operation strategy. At the end of the ride the electric charge of the battery remains at about $50 \%$. Using this strategy the operation intervals of the range extender are nearly constant except for the first operation interval. Here the battery heating starts from the thermal preconditioning level $\left(5^{\circ} \mathrm{C}\right)$ and must consequently be operated for a longer time. Afterwards the varying heat transfer due to the vehicle velocity is rather low so a thermally stationary state is reached.

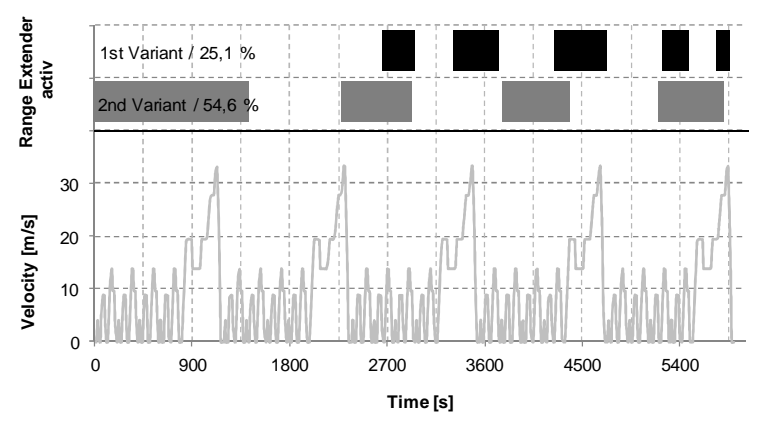

Fig. 11: Range extender operation

Next, the time dependent heat flow rate distributions of the different heating components are discussed. In the analysis it is assumed, that the electrical PTC heater has an efficiency of $100 \%$, so the electric demand and the heat flow rate are the same. When the internal combustion engine is not operated, its cooling circuit pump is switched off and the remaining heat is not used. This is illustrated in Fig. 12.

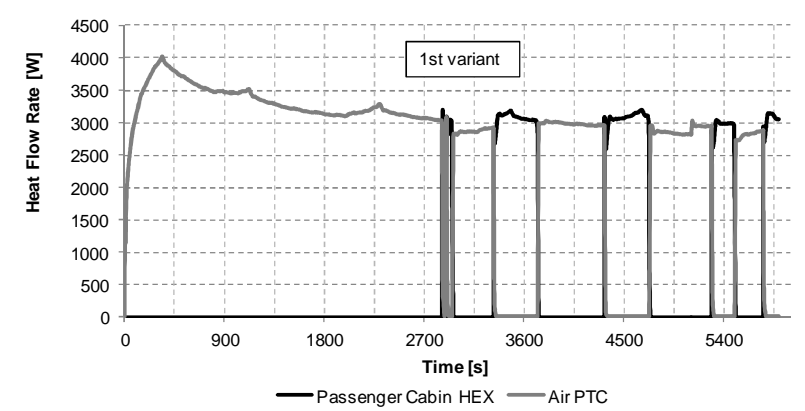

Fig. 12: Passenger cabin heating $1^{\text {st }}$ variant

Regarding variant 2 , Fig. 13 shows that due to the high temperature level of the battery's coolant circuit high COP-values are reached by the heat pump system so an efficient cover of the passenger cabin is achieved while operating purely electrically. 


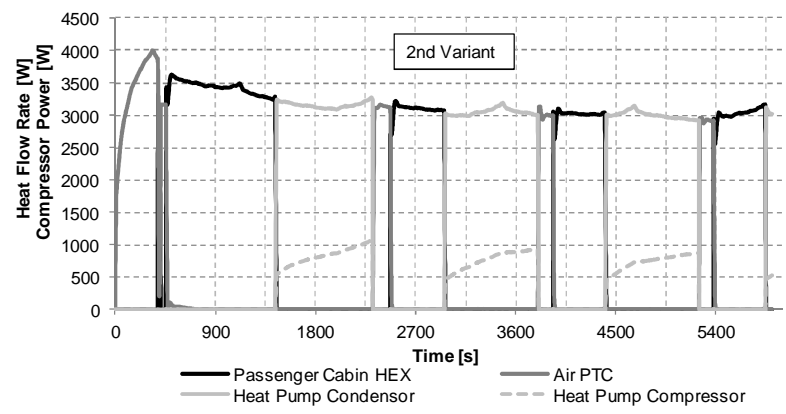

Fig. 13: Passenger cabin heating $2^{\text {nd }}$ variant

Furthermore, an energetic evaluation of both systems is performed. For the sake of comparability, the amount of used primary energy is evaluated for the two variants. In order to evaluate the overall efficiency the overall energy input has to be accumulated. For the discussed variants two different kind of energy forms are used, fuel and electric energy from the grid. For this analysis a primary energy factor of 1.26 is chosen for the fuel (cf. [12]) and 2.6 for electric energy (cf. [13]). This approximately corresponds to the energetic supply situation in Germany.

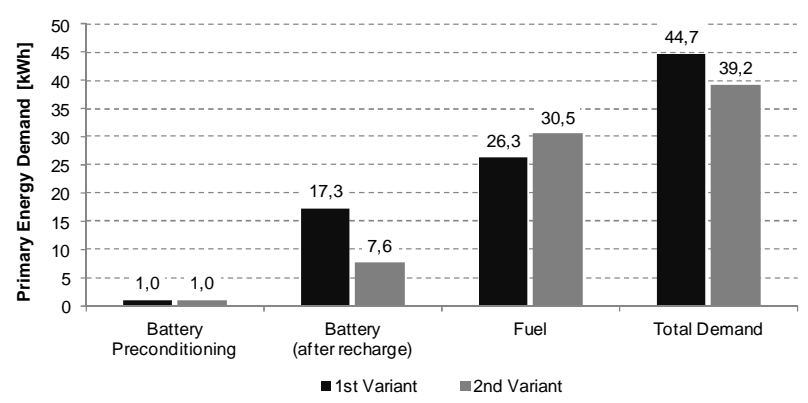

Fig. 14: Primary energy demand for both variants

The results show primary energy saving up to $12 \%$ for architecture 2 in combination with a thermal operational strategy. Thus, for the considered winter scenario the benefit of a cogeneration approach in combination with a heat pump and a thermal storage is clearly stated out.

\section{Conclusion}

The increasing complexity of actual and future vehicle leads to the need of a holistic modeling development tool taking into account all the classical automotive disciplines such as longitudinal dynamics, electric system or thermal management but also their connection vis-à-vis. Such a holistic library is currently being developed at Forschungsgesellschaft Kraftfahrwesen $\mathrm{mbH}$ Aachen (fka) and Institute of
Automotive Engineering (ika) of RWTH Aachen University and was presented in the paper.

An application example was given of the traction battery as a thermal storage of range extended electric vehicles. In the example the benefit of an enhanced cogeneration is shown. A further advantage of such an approach is that the traction battery will mostly be operated in an optimal temperature range and thus, best charge/discharge efficiencies and lifetimes are reached if the range is wisely chosen. However, the influence of this control strategy on the battery's lifetime has to be investigated further on. Due to the scalability of the model library a highly detailed model to determine lifetime strategies of the battery could be chosen for that or/and experimental could be carried out.

\section{References}

[1] M. Jung, A. Kemle, T. Strauss, und M. Wawzyniak, „Innenraumheizung von Hybridund Elektrofahrzeugen“, ATZ - Automobiltechnische Zeitschrift, Nr. 05/2011, 2011.

[2] P. Jeck, C. Bouvy, T. Lichius, und L. Eckstein, „Holistic method of thermal management development illustrated by the example of the traction battery for an electric vehicle", presented at the 20th Aachen Colloquium „Automobile and Engine Technology", Aachen, 2011.

[3] Modelica Association, „Modelica ${ }^{\circledR}$ - Release Notes of the Modelica Standard Library Version 3.2“, 2010.

[4] R. Franke, F. Casella, M. Sielemann, K. Proelss, M. Otter, und M. Wetter, „Standardization of Thermo-Fluid Modeling in Modelica.Fluid“", in Proceedings 7th Modelica Conference, Como, 2009.

[5] M. Dempsey, M. Gäfvert, P. Harman, C. Kral, M. Otter, und P. Treffinger, „Coordinated automotive libraries for vehicle system modelling", in Proceedings 5th Modelica Conference, Vienna, 2006.

[6] C. Bouvy, P. Jeck, J. Gissing, T. Lichius, S. Baltzer, und L. Eckstein, „Die Batterie als thermischer Speicher: Auswirkung auf die Innenraumklimatisierung, die thermische Architektur und die Betriebsstrategie von Elektrofahrzeugen", Wärmemanagement des Kraftfahrzeugs, Bd. VIII, Essen 2012.

[7] C. Bouvy, T. Lichius, und P. Jeck, „On the influence of the thermal demand on the overall 
efficiency of future drive train architectures for passenger cars", Int. J. Electric and Hybrid Vehicles, Bd. Vol. 3, Nr. No. 3, 2011.

[8] B. Hartmann und C. Renner, „Conventional HEV, Plug-In or Range Extender? A conceptual comparison of modern HEVs based on simulations“, presented at the 18th Aachen Colloquium „Automobile and Engine Technology“, Aachen, 2009.

[9] C. Bouvy, P. Jeck, S. Baltzer, J. Gissing, T. Lichius, und L. Eckstein, „The battery as thermal storage in range extender vehicles: Influence on the architecture and the operating strategy", in Hybrid and Electric Drivetrains 2012, Aachen.

[10] N. C. Strupp und N. Lemke, ,Klimatische Daten und Pkw-Nutzung: Klimadaten und Nutzungsverhalten zu Auslegung, Versuch und Simulation an Kraftfahrzeug-Kälte/Heizanlagen in Europa, USA, China und Indien“, Frankfurt a. Main, 2009.

[11] C. Bouvy, T. Lichius, und P. Jeck, „On the influence of cabin heating on the overall efficiency of car concepts", presented at the 20th Aachen Colloquium „Automobile and Engine Technology“, Aachen, 2011.

[12] R. Frischknecht und M. Tuchschmid, „Primärenergiefaktoren von Energiesystemen“, Aachen, 2009.

[13] N.N., Verordnung über energiesparenden Wärmeschutz und energiesparende Anlagentechnik bei Gebäuden (Energieeinsparverordnung - EnEV). 2009. 